\title{
ANALISIS CACAT PRODUK KEMASAN WAFER DI PT. TKT MOJOKERTO
}

\author{
Ika Widya Ardhyani ${ }^{1}$, Sugeng Santoso ${ }^{2}$ \\ Teknik Industri, Fakultas Teknik \\ Universitas Maarif Hasyim Latif, Sidoarjo, Indonesia \\ e-mail: 1ika_widya@dosen.umaha.ac.id, 2sugeng_s@gmail.com
}

Diterima: 20 Oktober 2020. Disetujui : 21 Desember 2020. Dipublikasikan : 30 Desember 2020

(C)2020 -TESJ Fakultas Teknik Universitas Maarif Hasyim Latif. Ini adalah artikel dengan

akses terbuka di bawah lisensi CC BY 4.0 (https://creativecommons.org/licenses/by/4.0/)

\begin{abstract}
ABSTRAK
PT. TKT merupakan perusahaan yang bergerak dalam bidang industri kertas. Namun dalam proses produksinya masih ditemukan kendala dan permasalahan yakni masih adanya cacat produk yang dapat mempengaruhi kualitas produk. Produk kemasan wafer yang diproduksi oleh PT. TKT mengalami cacat produksi berupa: warna (tidak sesuai CT, ada bercak, pudar), kemasan (terkena oli, sobek, basah), lem (lem lepas dan lem penguci lepas). Untuk mengatasi masalah kualitas produksi tersebut perlu dilakukan pengendalian kualitas dengan metode Six sigma untuk meningkatkan kualitas produksi. Pada tahap define jenis cacat yang terjadi sebanyak delapan jenis. Pada tahap measure diperoleh nilai DPMO sebesar 134.298 dengan nilai sigma sebesar 2,8. Dari hasil analisis diperoleh faktor-faktor penyebab cacat pada produk diantaranya: cara pengeliman yang kurang efektif, kurangnya pemerikasaan terhadap proses, faktor operator, dan faktor lingkungan kerja.
\end{abstract}

Kata kunci: kualitas, cacat produk, dpmo, six sigma

\begin{abstract}
PT. TKT is a company engaged in the paper industry. However, in the production process there are still obstacles and problems, namely there are still product defects that can affect the quality of the product. Wafer products manufactured by PT. TKT experiences production defects in the form of: color (not according to CT, spots, faded), packaging (exposed to oil, torn, wet), glue (loose glue and loose washing glue). To overcome these production quality problems it is necessary to carry out quality control methods Six sigma to improve production quality. At the define stage, the type of defect that occurs are eight defects. At the measure stage, the DPMO value is 134,298 with a sigma value of 2.8 . From the analysis results, the factors that cause defects in the product are obtained, including: ineffective method of settlement, lack of examination of the process, operator factors, and work environment factors.
\end{abstract}

Keywords: quality, product defects, dpmo, six sigma

\section{PENDAHULUAN}

PT. TKT adalah perusahaan yang berproduksi di bidang kertas selama 25 tahun, yang merupakan salah satu pabrik kertas terbesar yang ada di Indonesia. PT. TKT memiliki Divisi Printing Packaging yang berlokasi di Jalan Raya Surabaya-Mojokerto km.44 Desa Kramat Temenggung Kecamatan Tarik, Kabupaten Sidoarjo.

Demi menjaga pelayanan dan kepuasan konsumen PT. TKT berusaha memberikan pelayanan prima untuk menjaga kualitas produknya, namun dalam melakukan proses produksi beberapa mengalami kendala dan permasalahan yakni masih ditemukannya produk cacat yang dapat mempengaruhi kepuasan pelanggan.

Produk kemasan yang diproduksi oleh PT. TKT mengalami cacat produksi berupa; warna tidak sesuai CT, bercak, pudar, kemasan terkena oli, sobek, basah, lem lepas dan lem pengunci lepas.

Untuk mengatasi masalah kualitas produksi tersebut perlu dilakukan pengendalian kualitas produk dengan metode Six sigma untuk meningkatkan kualitas produksi.

\section{METODE PENELITIAN}

Data penelitian diperoleh dari PT. TKT. Adapun data yang digunakan adalah data produk cacat, data proses produksi, data jumlah produksi, 
selama 14 bulan dari bulan Desember 2018 hingga bulan Januari 2020. Data produk yang diteliti yakni pada produk kemasan wafer PT. TKT. Analisis dalam penelitian ini dilakukan dengan pendekatan Six Sigma.

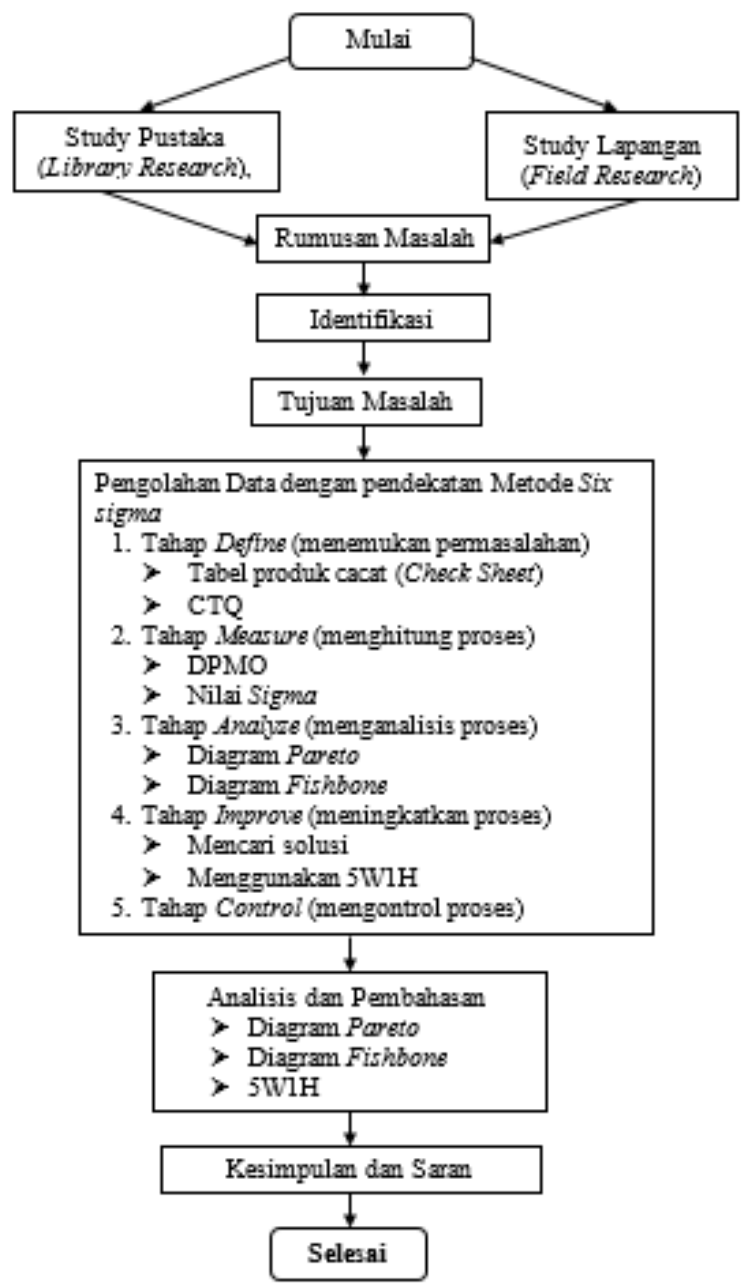

Gambar 1. Fowchart Penelitian

\section{Tahap Define}

Dalam tahap define dilakukan identifikasi masalah dengan melakukan wawancara guna melakukan pemetaan proses produksi untuk menganalisis adanya cacat produk dengan menggunakan tabel checksheet. Langkah selanjutnya dilakukan identifikasi Critical to Quality (CTQ) dari produk atau proses agar dapat mencapai performansi standar atau batas/limit dari spesisikasi agar dapat memuaskan keinginan dan kebutuhan pelanggan.

\section{Tahap Measure}

Dalam tahap measure ini dilakukan tahap pengukuran terhadap performansi dari sigma dengan tujuan mengetahui baseline dari suatu kinerja. Adapun baseline kinerja dari PT. TKT dihitung DPMO (Defect Per Million Opportunities) dan nilai sigma.

$$
\mathrm{DPO}=\frac{\text { Tumlah Produk Cacat }}{\text { Tumlah total diprodukaj } \times \text { CTQ }}
$$

$$
\mathrm{DPMO}=\mathrm{DPO} \times 1.000 .000
$$

Nilai DPMO dikonversi menjadi nilai sigma dengan menggunakan microsoft excel, adapun rumus perhitungan konversi nilai DPMO (Gaspersz, 2002):

NilaiSigma $=n o r m \sin v\left(\frac{1.000 .000-D P M O}{1.000 .000}\right)+1,5$

Hasil Nilai Sigma merupakan ukuran yang menyatakan seberapa besar kemampuan suatu proses atau dapat diartikan seberapa sering kemungkinan terjadi produk cacat, semakin besar nilai sigma maka proses dinilai semakin baik.

Tabel 1. Tingkat Pencapaian Nilai Sigma (Gaspersz \& Fontana, 2011)

\begin{tabular}{l|l}
\hline $\begin{array}{l}\text { Tingkat } \\
\text { Pencapaian } \\
\text { Sigma }\end{array}$ & DPMO \\
\hline 1-Sigma & 691.462 \\
\hline 2-Sigma & 308.538 (Rata-rata Industri Indonesia) \\
\hline 3-Sigma & 66.807 \\
\hline 4-Sigma & 6.210 (Rata-rata Industri USA) \\
\hline 5-Sigma & 233 (Rata-rata Industri Jepang) \\
\hline 6-Sigma & 3,4 \\
\hline
\end{tabular}

\section{Tahap Analyze}

Dalam tahap ini dilakukan pengidentifikasian sumber dan akar dari penyebab dari cacat produk dalam suatu proses.

\section{Tahap Improve}

Tahap improve merupakan tahap untuk memberikan usulan perbaikan yang sesuai dengan hasil analisis permasalahan yang telah dilkukan pada tahap sebelumnya. Adapun tujuan dari tahap ini adalah agar proses dapat terkendelai dan mencegah agar tidak terjadi permasalahan yang menimbulkan cacat produk.

\section{HASIL DAN PEMBAHASAN}

Dalam pengolahan data dilakukan dengan menggunakan pendekatan metode Six Sigma DMAI yakni Define (mengidentifikasi permasalahan), Measure (menghitung proses), Analyze (menganalisis proses), Improve (meningkatkan proses).

\section{Tahap Define}


Tahap awal dalam dalam penelitian ini adalah mengidentifikasi permasalahan.

Yang terlebih dahulu dijelaskan spesifikasi standar produk pada PT. TKT pada produk wafer adalah:

1. warna sesuai CT (Color Tolerance)

2. warna tidak mengalami pudar

3. warna tidak timbul bercak

4. hasil cutting register

5. hasil varnish glossy

6. bentuk box presisi

7. hasil creasing presisi

8. daya rekat lem kuat

9. hasil lem tidak over glue

Tabel 2. Data jumlah produksi dan cacat produk kemasan wafer Desember 2018-Januari 2020 PT. TKT

\begin{tabular}{|c|c|c|c|c|}
\hline No. & Bulan & Tahun & $\begin{array}{c}\text { Jumlah } \\
\text { produk } \\
\text { Cacat }\end{array}$ & $\begin{array}{l}\text { Jumlah } \\
\text { produksi }\end{array}$ \\
\hline 1 & Desember & 2018 & 23.133 & 8.133 .200 \\
\hline 2 & Januari & 2019 & 52.333 & 8.563 .200 \\
\hline 3 & Februari & 2019 & 108.483 & 7.580 .200 \\
\hline 4 & Maret & 2019 & 46.689 & 6.410 .400 \\
\hline 5 & April & 2019 & 83.371 & 6.136 .600 \\
\hline 6 & Mei & 2019 & 56.184 & 5.439 .600 \\
\hline 7 & Juni & 2019 & 13.498 & 6.382 .600 \\
\hline 8 & Juli & 2019 & 31.192 & 2.472 .000 \\
\hline 9 & Agustus & 2019 & 71.344 & 10.639 .197 \\
\hline 10 & September & 2019 & 36.277 & 3.252 .620 \\
\hline 11 & Oktober & 2019 & 22.686 & 4.053 .800 \\
\hline 12 & November & 2019 & 41.782 & 1.532 .400 \\
\hline 13 & Desember & 2019 & 4.304 & 40.000 \\
\hline 14 & Januari & 2020 & 61.442 & 8.189 .600 \\
\hline & & Jumlah & 652.718 & 78.825 .417 \\
\hline
\end{tabular}

Tahap Measure

Pengukuran

dilakukan

dengan menggunakan diagram kontrol P-Chart.

Mean (CL) atau rata-rata produk akhir bisa dihitung dengan cara sebagai berikut:

$$
\mathrm{CL}=\frac{\sum \mathrm{np}}{\sum \mathrm{n}}
$$

Jumlah proporsi produk akhir mingguan (P), produk akhir (np) dibagi dengan sampel (n):

$$
\mathrm{P}=\frac{\mathrm{np}}{\mathrm{n}}
$$

Jumlah batas kendali atas (UCL)

$$
\mathrm{UCL}=\mathrm{p}+3 \frac{\sqrt{p(1-p)}}{n}
$$

Jumlah batas kendali bawah (LCL)

$$
\mathrm{LCL}=\mathrm{p}-3 \frac{\sqrt{p(1-p)}}{n}
$$

Pada Gambar 2 ditunjukan bahwa kapabilitas proses belum berjalan dengan baik hal ini ditunjukkan oleh peta kontrol bahwa data berada di luar batas kendali atas dan batas kendali bawah.

\section{Tahap Pengukuran Defect Per Million Opportunities (DPMO) dan Tingkat Sigma}

Dalam tahap ini dilakukan pengukuran performansi nilai sigma dengan tujuan untuk mengetahu tingkat kerja saat ini.

Penentuan CTQ (Critical to Quality) pada proses produksi kemasan wafer karakteristik yang menyebabkan hasil produksi tidak sesuai harapan pelanggan terbagi menjadi delapan kategori yaitu: warna (tidak sesuai CT, terdapat bercak, pudar); kemasan (terkena oli, sobek, basah); lem (lem lepas, lem pengunci lepas).

\section{Menghitung Defect Per Opportunity (DPO)}

$$
\mathrm{DPO}=\frac{\text { Tumlah Produk Cacat }}{\text { Tumlah total diprodukaj } \mathrm{x} \mathrm{CTQ}}
$$

\section{Menghitung Defect Per Million Opportunities (DPMO)}

$$
\mathrm{DPMO}=\mathrm{DPO} \times 1.000 .0000
$$

Dari hasil perhitungan dalam Tabel 3 diketahui bahwa proses produksi kemasan wafer di PT. TKT memiliki kapabilitas proses yang masih

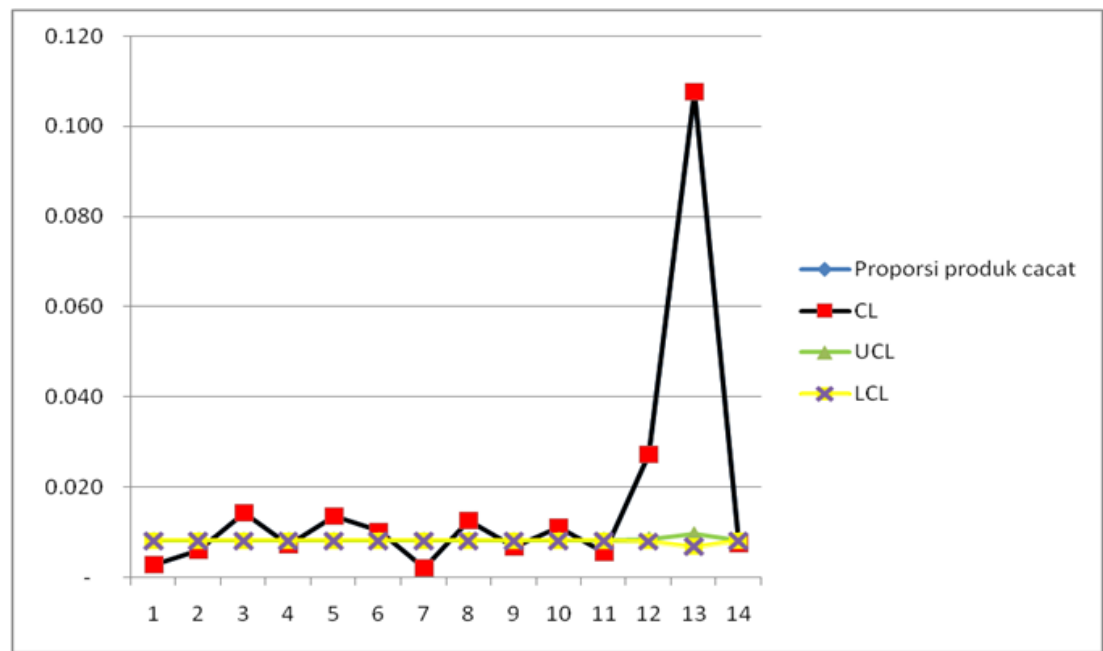

Gambar 2. Peta Kendali P Produk Kemasan Wafef PT. TKT 
rendah. Hal ini ditunjukkan dengan nilai DPMO yang masih cukup tinggi, yaitu 134.298, yang dapat diartikan bahwa dalam satu juta kesempatan yang ada, masih terdapat 134.298 kemungkinan proses produksi tersebut menghasilkan produk cacat. Maka pengendalian kualitas harus terus ditingkatkan, agar tingkat cacat produk dapat diminimalisir. Tingkat kecacatan yang tinggi dapat menimbulkan kerugian yang besar terhadap perusahaan.

\section{Tahap Analisis (Analyze)}

Tahap awal dalam analyze adalah mengetahui jenis cacat produk yang paling dominan. Hal ini ditunjukkan dengan digram pareto dimana berdasarkan Tabel 4 adalah warna tidak sesuai CT sebesar 247.202 pcs.

Berdasarkan hasil diagram pareto pada Gambar 3

Tabel 3. Kapabilitas Sigma, DPMO dari Proses Produksi Kemasn Wafer PT.TKT

\begin{tabular}{l|c|c|c|c|c|c|c}
\hline \multicolumn{1}{c|}{ Bulan } & Tahun & $\begin{array}{c}\text { Jumlah } \\
\text { Produksi }\end{array}$ & $\begin{array}{c}\text { Jumlah } \\
\text { Produk } \\
\text { cacat }\end{array}$ & $\begin{array}{c}\text { Banya } \\
\text { k CTQ }\end{array}$ & (DPO) & DPMO & $\begin{array}{c}\text { Nilai } \\
\text { Sigma }\end{array}$ \\
\hline Desember & 2018 & 8.133 .200 & 23.133 & 8 & 0.023 & 22.754 & 3.50 \\
\hline Januari & 2019 & 8.563 .200 & 52.333 & 8 & 0.049 & 48.891 & 3.16 \\
\hline Februari & 2019 & 7.580 .200 & 108.483 & 8 & 0.114 & 114.491 & 2.70 \\
\hline Maret & 2019 & 6.410 .400 & 46.689 & 8 & 0.058 & 58.267 & 3.07 \\
\hline April & 2019 & 6.136 .600 & 83.371 & 8 & 0.109 & 108.687 & 2.73 \\
\hline Mei & 2019 & 5.439 .600 & 56.184 & 8 & 0.083 & 82.630 & 2.89 \\
\hline Juni & 2019 & 6.382 .600 & 13.498 & 8 & 0.017 & 16.918 & 3.62 \\
\hline Juli & 2019 & 2.472 .000 & 31.192 & 8 & 0.101 & 100.945 & 2.78 \\
\hline Agustus & 2019 & 10.639 .197 & 71.344 & 8 & 0.054 & 53.646 & 3.11 \\
\hline September & 2019 & 3.252 .620 & 36.277 & 8 & 0.089 & 89.225 & 2.85 \\
\hline Oktober & 2019 & 4.053 .800 & 22.686 & 8 & 0.045 & 44.770 & 3.20 \\
\hline November & 2019 & 1.532 .400 & 41.782 & 8 & 0.218 & 218.126 & 2.28 \\
\hline Desember & 2019 & 40.000 & 4.304 & 8 & 0.861 & 860.800 & 0.42 \\
\hline Januari & 2019 & 8.189 .600 & 61.442 & 8 & 0.060 & 60.020 & 3.05 \\
\hline \multicolumn{1}{|c|}{ Jumlah } & & 78.825 .417 & 652.718 & & & 134.298 & 2,8 \\
\hline
\end{tabular}

Tabel 4. Hasil Perhitungan Persentase Cacat dan persentase Kumulatif kemasan wafer PT. TKT

\begin{tabular}{|c|c|c|c|c|}
\hline No. & Jenis Cacat & $\begin{array}{c}\text { Jumlah } \\
\text { Cacat }\end{array}$ & Persentase & $\begin{array}{c}\text { Persentase } \\
\text { Kumulatif }\end{array}$ \\
\hline 1. & Warna tidak sesuai CT & 247.202 & 37,87 & 37,87 \\
\hline 2. & Warna Pudar & 173.784 & 26,62 & 64,50 \\
\hline 3. & Lem Lepas & 135.281 & 20,73 & 85,22 \\
\hline 4. & Penguci Lepas & 67.177 & 10,29 & 95,52 \\
\hline 5. & Warna bercak & 27.339 & 4,19 & 99,70 \\
\hline 6. & Kemasan Basah & 1.335 & 0,20 & 99,91 \\
\hline 7. & Kemasan Terkena oli & 600 & 0,09 & 100 \\
\hline 8. & Kemasan Sobek & 0 & 0 & 100 \\
\hline \multicolumn{2}{|r|}{ Total } & 652.718 & $100 \%$ & \\
\hline
\end{tabular}

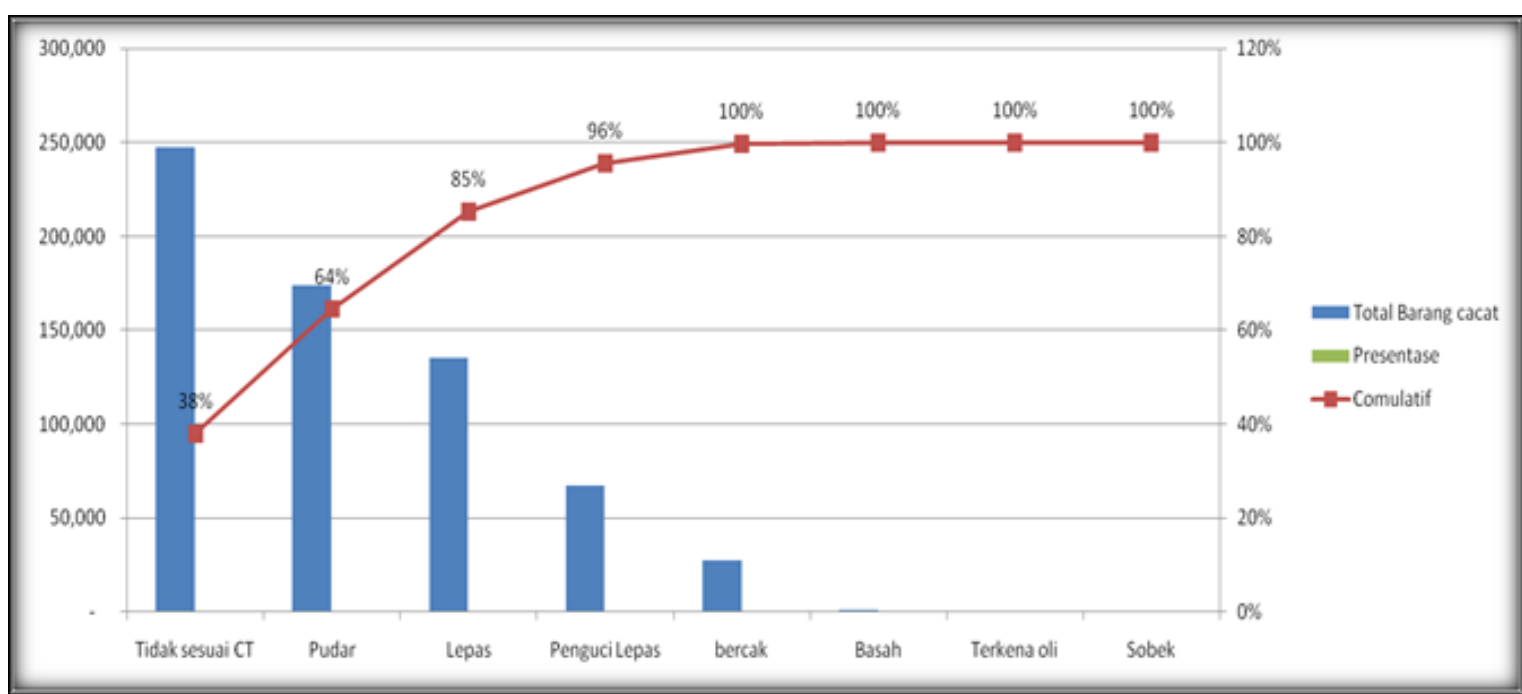

Gambar 3. Diagram Pareto Cacat Produk Kemasan Wafer PT. TKT 
Tabel 5. Usulan Tidakan Perbaikan

\begin{tabular}{c|l|l|l}
\hline No. & \multicolumn{1}{|c|}{ Jenis } & \multicolumn{1}{|c}{$\mathbf{5 W + H}$} & \multicolumn{1}{c}{ Deskripsi } \\
\hline 1. & Tujuan Utama & What (apa?) & $\begin{array}{l}\text { a. Meningkatkan peran struktural organisasi produksi } \\
\text { b. Meningkatkan kepatuhan karyawan. } \\
\text { c. Membikin skema pengecekan produksi secara berkala. } \\
\text { d. Menambah intensitas evaluasi bulanan }\end{array}$ \\
\hline 2. & Alasan Kegunaan & Why (mengapa) & $\begin{array}{l}\text { a. Untuk berjalannya jobdesk sesuai standarperusahaan. } \\
\text { b. Meningkatkan kedisplinan karyawan. } \\
\text { c. Meminimalkan angka kerusakan/cacatproduksi } \\
\text { d. Untuk memonitoring hasil kerja berdasarkan struktural organisasi }\end{array}$ \\
\hline 3. & Lokasi & Where (dimana) & PT. TKT. \\
\hline 4. & Sekuen (Urutan) & When (Kapan) & 2 bulan (April-Mei 2020) \\
\hline 5. & Orang & Who (siapa) & $\begin{array}{l}\text { a. Kepala Regu } \\
\text { b. Operator }\end{array}$ \\
\hline 6. & Metode & $\begin{array}{l}\text { How } \\
\text { (bagaimana) }\end{array}$ & $\begin{array}{l}\text { Melakukan breafing dan memberikan chek list baru selama proses } \\
\text { produksi untuk di isi dan dipatuhi guna menurunkan angka cacat } \\
\text { produksi }\end{array}$ \\
\hline
\end{tabular}

menunjukkan jenis kerusakan yang sering terjadi adalah pada warna tidak sesuai CT sebanyak 247.202 pcs atau $37,87 \%$, warna pudar sebanyak 173.784 pcs atau $26,62 \%$, lem lepas sebanyak 135.281 atau 20,73\%, penguci lepas sebanyak 67.177 pcs atau $10,29 \%$, warna bercak sebanyak 27.339 atau 4,19\%, kemasan basah sebanyak 1335 pcs atau 0,20\%, kemasan terkena oli sebanyak 600 pcs atau 0,09\%,dan kemasan sobek tidak terdapat cacat.

\section{Tahap Improve}

Pada tahap ini diberikan usulan perbaikan untuk peningkatan kualitas. solusi yang diberikan mengikuti action plan yang disusun dengan metode $5 \mathrm{~W}+1 \mathrm{H}$. Adapun usulan perbaikan untuk cacat produk yang terjadi pada kemasan wafer di PT. TKT ditunjukkan pada Tabel 5.

\section{PENUTUP}

Faktor-faktor yang menyebabkan produk cacat pada produk kemasan wafer di PT. TKT yakni :faktor manusia (Operator dan Asisten Oprator) yang kurang teliti, tidak konsentrasi, tidak taat, skill/kemampuan berbeda, metode yang diberi dijalankan dengan benar (S.O.P tidak jalankan, Peran Karu kurang maksimal, metting mingguan tidak maksimal), usia mesin yang terlalu tua dan material lem kwalitas berubah ubah tidak bisa konsisten sehingga menjadi masalah serius dalam masa produksi.

\section{DAFTAR PUSTAKA}

Ahyari, A. (2000). Manajemen Produksi Perencanaan Sistem Produksi Buku II. Yogyakarta: BPFE.
Amrullah, Siburian, P. S., \& Zainurossalamia, S. (2016). Pengaruh Kualitas Produk dan Kualitas Layanan Terhadap Keputusan Pembelian Sepeda Motor Honda. KINERJA: Jurnal Ekonomi Dan Manajemen, 13(2).

Dewangga, F. S. (2019). Analisis Penurunan Jumlah Cacat pada Produk Wafer Stik Salut dengan Pendekatan Six Sigma di PT. C. Prosiding SemNas Teknik UMAHA. Sidoarjo: Fakultas Teknik UMAHA.

Dewi, A. M., \& Puspitasari, N. B. (2018). Analisis Pengendalian Kualitas Menggunakan Metode Six Sigma pada Produk AMDK 240 ml PT. Tirta Investama Klaten. Industrial Engineering Online Journal, 7(4).

Fridyawati, F. (2015). Analisis Pengendalian Kualitas pada Defect Produk Kemasan Kaleng dengan Metode Six Sigma (Studi Kasus: PT Kedaung Indah Can Tbk) (Teknik Industri, Universitas Brawijaya). Retrieved from http://repository.ub.ac.id/id/eprint/14354 1

Gaspersz, V. (2002). Pedoman Implementasi Program Six Sigma: Terintegrasi Dengan ISO 9001:2000, MBNQA dan HACCP. Jakarta: PT. Gramedia Pustaka Tama.

Gaspersz, V. (2006). Total Quality Management (TQM): Untuk Praktisi dan Bisnis dan Industri. Jakarta: Gramedia Pustaka Utama.

Gaspersz, V., \& Fontana, A. (2011). Lean six sigma for manufacturing and service industries: waste elimination and continuous cost reduction. Bogor: Vinchristo Publication.

Tumanan, D., \& Poniran, Y. R. N. (2016). Analisis Pengendalian Kualitas Kemasan dan Produk Air Galon 19 Liter dengan Metode Six Sigma pada CV. Lestari Multi Usaha. ARIKA, 10(2). 
IW Ardhyani, dkk / Teknika : Engineering and Sains Journal, Vol. 4, No.2, Desember 2020, 43-48

halaman ini sengaja dikosongkan 